\title{
The Intracranial and Posterior Cranial Fossa Volumes and Volume Fractions in Children: A Stereological Study
}

\author{
Los Volúmenes de la Fosa Craneal Intracraneal y Posterior y las Fracciones \\ de Volumen en los Niños: Un Estudio Estereológico
}

Tolga Ertekin'; Muhammet Degermenci²; Ilyas Ucar ${ }^{3}$; Ayse Sagıroglu² Emre Atay ${ }^{4}$ \& Hatice Susar ${ }^{2}$

ERTEKIN, T.; DEGERMENCI, M.; UCAR, I.; SAGIROGLU, A.; ATAY, E. \& SUSAR, H. The intracranial and posterior cranial fossa volumes and volume fractions in children: A stereological study. Int. J. Morphol., 35(4):1465-1472, 2017.

SUMMARY: The size of intracranial cavity (IC) and posterior cranial fossa (PCF) plays an important role in the pathophysiology of various disorders. In this study, we aimed at establishing normal volume data of the IC and PCF in Turkish population according to age and sex by using stereological method. This study was carried out retrospectively on 339 individuals (168 females and 171 males) between 0 and 18 years old with no medical or neurological disorders that affected the skeletal morphology of the cranial cavity. Volumetric estimations were determined on computed tomography (CT) images using point-counting approach of stereological methods. Intracranial volume (ICV) and posterior cranial fossa volume (PCFV) were increased with age in both sexes. They reached adult dimensions at 5 years of age during the teenage years. According to sex; the mean ICV and PCFV were $1594.51 \pm 245.57 \mathrm{~cm}^{3}$ and $244.89 \pm 53.86 \mathrm{~cm}^{3}$ in males, $1456.34 \pm 241.85 \mathrm{~cm}^{3}$ and $228.24 \pm 41.38 \mathrm{~cm}^{3}$ in females, respectively. Generally, significant differences were determined in ICV and PCFV according to sex after they reached maximum growth period. According to age the volume ratios of PCF to IC was ranged from 13.03 to 17.48 in males and 12.06 to 18.54 in females. This study demonstrated that these volume ratios could help the physician for both patient selections for surgery, and for the assessment of any surgical technique used to treatment of PCF malformations. However current study revealed that point counting method can produce accurate volume estimations and is effective in determining volume estimation of IC and PCF.

KEY WORDS: Computed tomography; Intracranial cavity; Posterior Cranial Fossa; Stereology; Volume.

\section{INTRODUCTION}

Intracranial volume (ICV), sometimes referred to as total intracranial volume, attributes to the estimated volume of the cranial cavity as outlined by the supratentorial dura matter or cerebral contour when dura is not clearly detectable (Eritaia et al., 2000). Recent studies measured ICV to investigate progressive neurodegenerative brain disorders, such as Alzheimer's disease (Dukart et al., 2013), age-related changes in the structure of premorbid brain (Szentkuti et al., 2004). ICV consistency during aging makes it a reliable tool for correction of head size variation across subjects in studies that rely on morphological features of the brain (Ikram \& DeCarli, 2012). In addition, craniosynostosis, the premature fusion of one or more cranial sutures, changes the normal morphology of the growing cranial vault. The two profound functional concerns with premature fusion are the probable reduction in craniofacial skeletal growth and the possible elevation in intracranial pressure. The relationship between them is still not clear. The earliest methods for measuring the craniofacial skeleton were based on anthropometric measurements of head (Bambha, 1961). The ICV measurement may be more directly related to intracranial pressure than any linear measurement of the calvaria. In vivo measurement of ICV was not possible until the advent of nowadays sectional imaging technics. The accurate measurement of intracranial pressure is valuable but generally requires invasive techniques. ICV can be accurately measured with modern computed tomography and MR imaging. Approaches at creating a standard reference of ICV's have been made in the past but have been limited either by using volume estimation techniques or by small

\footnotetext{
${ }^{1}$ Department of Anatomy, University of Afyon Kocatepe, Afyonkarahisar, Turkey.

${ }^{2}$ Department of Anatomy, University of Erciyes, Kayseri, Turkey.

${ }^{3}$ Department of Physical Therapy and Rehabilitation, Ahi Evran University, Kirsehir, Turkey.

${ }^{4}$ Vocational School of Health Services, University of Kilis 7 Aralık, Turkey.
} 
sample sizes (Sgouros et al., 1999). The volume of organs or structures can be obtained using the Cavalieri principle of stereologic approaches (Cruz-Orive, 1997). The requirement for the application of this method is a complete set of parallel two-dimensional slices through the object which are separated by a known distance, and begin randomly within the object, and criteria were met by standard MR imaging and computed tomography (CT) scanning techniques (Roberts et al., 2000; Sahin \& Ergur, 2006). In addition recents radiologic studies demostrated that point counting and fluid displacement (the gold standard) methods were agreement each other for volume estimation of region of intrest (Nisari et al., 2012).

The posterior cranial fossa $(\mathrm{PCF})$ is a compact region that contains many structures that are vital to life. Configuration and size of the posterior fossa (PF) plays an important role in the pathophysiology of various disorders of the PF and craniovertebral junction (Wang et al., 1987; Bagley et al., 2006). A wide spectrum of central nervous system (CNS) diseases in children have been associated with alterations in the size of the PCF or its contents. Several studies have compared PCF dimensions in patients with these conditions with those in control individuals (Kollias et al., 1993; Trigylidas et al. 2008; Furtado et al., 2009). Although normative data could indirectly be derived from the control groups of these studies, few studies establish normative values for PCF dimensions (Habibi et al., 2011; Chadha et al., 2015).

The purpose of current study was to investigate development and to establish normative data of ICV, PCFV and volume fraction of PCF in a homogeneous Turkish population according to age and sex by using stereological method.

\section{MATERIAL AND METHOD}

This study was carried out retrospectively on sagittal scan images taken from 339 Turkish individuals (168 females and 171 males) aged between 0-18 years who had been admitted to Erciyes University Medical Faculty. Subjects were selected from a larger pool of individuals and children with any medical or neurological disorders that affected the skeletal morphology of the cranial cavity were excluded. Inclusion into the study required a negative computed tomography report for any pathology, reviewed by a pediatric radiologist. The CT images were examined to exclude the maxillofacial deformities, intracranial tumours or infarcts and other related diseases which could impact the development of cranium and its morphology and anatomy.The present study was approved by the ethical committee of Erciyes University, Turkey.

CT procedure. We analyzed the intact cranial CT images of all the subjects. The CT images were prepared using the following protocol. The sagittal CT scans of cranial images were obtained using a CT scanner (Multislice 16 detector GE) applying the following parameters; kV: 120, mAs: 130, FOV (field of view): $24-25 \mathrm{~cm}$, section time: $2.7 \mathrm{sec}$, slice thickness: $0.7 \mathrm{~mm}$. CT images were taken from sagittal plan from Picture Archive and Communication System (PACS).

The margins of the posterior cranial fossa. The posterior cranial fossa was defined as the osseous anatomical area with a floor formed by the occipital bone (basiocciput portion of the clivus and supraocciput portion of the occipital bone up to the insertion of the tentorium cerebelli, which formed the superior boundary of this fossa) and the basisphenoid. The petrous ridges of the temporal bones formed the anterolateral border of this cavity anteriorly to their connection (posterior petroclinoid ligament) to the posterior clinoids (Tubbs et al., 2008).

Cavalieri principle applied to CT sections and stereological analysis. Point-counting method is based on the Cavalieri principle that is used for an unbiased estimation of volume of any structure (Gundersen et al., 1999). Using the Cavalieri method (point counting), an estimate of the volume of a structure of irregular shape and size may be obtained influentially and with known precision (Roberts et $a l$.). According to this method, the CT images of a section series $0.7 \mathrm{~mm}$ thickness were used to estimate the region of interest (ROI) volume. The films were displayed on computer and the transparent square grid test system with $\mathrm{d}=0.3 \mathrm{~cm}$ between the test points was superimposed, randomly covering the entire image frame (Fig. 1). The points hitting the ROI-sectioned surface area were counted for each section and the volumes of ICV and PCFV were estimated using the modified Equation 1 (Sahin et al., 2007).

$$
V=t \times\left[\frac{S U \times d}{S L}\right]^{2} \times \sum P
$$

Where $\mathrm{t}$ is the section thickness of consecutive sections, $\mathrm{SU}$ is the scale unit of the printed film, $\mathrm{d}$ is the distance between the points of the grid, SL is the measured length of the scale printed on the film. $\sum \mathrm{P}$ is the total number of points hitting the sectioned cut surface areas of region of interest. 


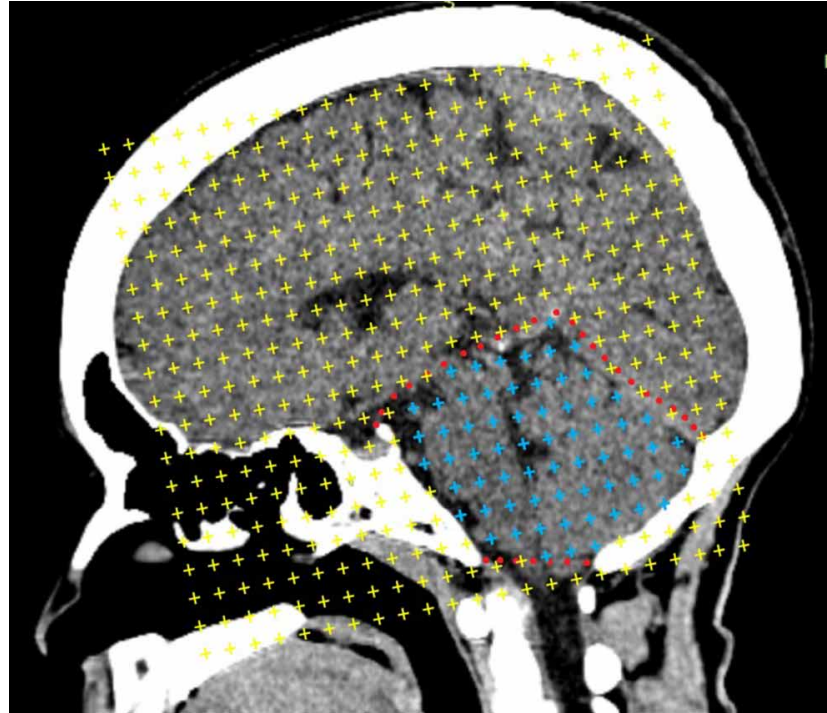

Fig. 1. Estimation of intracaranial cavity and posterior cranial fossa on sagittal computed tomography images by superimposing randomly the point-counting grid.

Volume fraction estimation. Volume is a simple and very widely used parameter in biomedical science (Mattfeldt $e t$ al., 2003). It is used to express the proportion of a phase or component within the whole structure. The volume fraction of an X phase within a Y reference volume is simply expressed as follows (Eq. 2):

$$
V v(X, Y)=\frac{\text { Volume of } \mathrm{X} \text { phase in } \mathrm{Y} \text { reference space }}{\text { Volume of } \mathrm{Y} \text { reference space }}
$$

Where the $\mathrm{Vv}(\mathrm{X}, \mathrm{Y})$ indicates volume fraction of $\mathrm{X}$ phase within the $\mathrm{Y}$ reference volume. Volume fraction rates change between 0 and 1 and is often expressed as a percentage (Howard \& Reed, 2005).

The volume fraction of a phase can be estimated by means of the Cavalieri principle on radiological images using point-counting approach. The volume fraction formula with the point-counting grid can be written as following Eq. (3).

$$
V v(X, Y)=\frac{\sum \mathrm{Px}}{\sum \mathrm{Py}}
$$

Where ' $\Sigma \mathrm{Px}$ ' indicates the number of points hitting the $\mathrm{X}$ phase and ' $\Sigma \mathrm{Py}$ ' the number of points hitting the reference space $\mathrm{Y}$.
We estimated the volume fraction of the PCF within the IC by means of volume fraction approach, i.e. the PCFV within the ICV using the following formula (Eq. 4).

$V v($ posterior cranial fossa, intracranial $)=\frac{\sum \mathrm{P} \text { posterior cranial fossa }}{\sum \mathrm{P} \text { intracranial cavity }}$

Where, $\mathrm{SP}_{\text {posterior cranial fossa }}$ is the total number of points hitting the components of posterior cranial fossa and $\mathrm{SP}_{\text {intracranial cavity }}$ is the total number of points hitting sectioned surface of intracranial cavity including all parts.

The volume fraction of the PCF volume within the IC was estimated as:

$V v$ (posterior cranial fossa, intracranial cavity) $=\frac{\sum \text { P posterior cranial fossa }}{\sum \mathrm{P} \text { intracranial cavity }}$

$$
\begin{aligned}
=\frac{260 \mathrm{~cm}^{3}}{1624 \mathrm{~cm}^{3}} & =0.16=16 \% .
\end{aligned}
$$

The coefficient of error (CE) for point counting. The coefficient of error (CE) of the point-counting method was calculated using the formula described in previous study (Gundersen et al.). A lower CE value than $5 \%$ is an acceptable range according to the literature. It is important to note that the $\mathrm{CE}$ has no real biological meaning. Rather, it is most useful for evaluating the precision of stereological estimates. It is also important to note that an appropriate grid size and the number of slices required for volume estimation of an object are crucial at the beginning.

Statistical analysis. All statistical analyses were performed with the Statistical Package for the Social Sciences software (Version 16.0; SPSS, Chicago, IL, USA).The comparing of the volume results between sexes were analyzed using the Independent $t$ test and comparison of the results of ICV and PCFVwere analyzed using pair samples $t$ test. Results have been expressed as the number of observations and mean \pm Standard Deviation (SD). A p value less than 0.05 was considered as statistically significant.

\section{RESULTS}

The mean ICV and PCFV's volumes were $1527.22 \pm 253.89 \mathrm{~cm}^{3}$ and $236.86 \pm 48.71 \mathrm{~cm}^{3}$ respectively. The ICV and PCFV's results were shown in Table I. Age-related changes in ICV and PCFV in general similar and positive correlation was found between age and them. They reached adult dimensions at 5 years of age during the teenage years (Table I, Fig. 2). 
Table I. The mean volumes of posterior cranial fossa and intracranial cavity according to age calculated by using stereological method ICV: Intracranial volume, PCFV: Posterior cranial fossa volume, ${ }^{*} \mathrm{p}<0.05$.

\begin{tabular}{|c|c|c|c|c|c|c|c|}
\hline \multirow{3}{*}{$\begin{array}{c}\text { Age } \\
1\end{array}$} & \multirow{2}{*}{$\begin{array}{l}\text { Parameter } \\
\text { ICV }\end{array}$} & \multirow{2}{*}{\begin{tabular}{l|}
$\mathbf{N}$ \\
20
\end{tabular}} & \multirow{2}{*}{\begin{tabular}{|c|} 
Min \\
450.72 \\
\end{tabular}} & \multirow{2}{*}{$\begin{array}{r}\text { Max } \\
1420.31\end{array}$} & \multicolumn{2}{|c|}{ Mean \pm SD } & \multirow{2}{*}{$\begin{array}{c}\begin{array}{c}\text { Volume } \\
\text { fraction }\end{array} \\
16.23\end{array}$} \\
\hline & & & & & 972.77 & 263.91 & \\
\hline & PCFV & 20 & 115.34 & 229.41 & 157.85 & 35.16 & \\
\hline \multirow[t]{2}{*}{2} & ICV & 16 & 997.92 & 1505.95 & 1210.26 & 150.72 & 15.04 \\
\hline & PCFV & 16 & 111.78 & 247.21 & 181.97 & 35.22 & \\
\hline \multirow[t]{2}{*}{3} & ICV & 19 & 889.38 & 1714.61 & 1418.62 & 196.75 & 17.78 \\
\hline & PCFV & 19 & 153.90 & 330.48 & 252.22 & 43.89 & \\
\hline \multirow[t]{2}{*}{4} & ICV & 20 & 1166.40 & 1864.62 & 1521.61 & 194.17 & 17.84 \\
\hline & PCFV & 20 & 185.33 & 332.42 & 271.48 & 46.57 & \\
\hline \multirow[t]{2}{*}{5} & ICV & 18 & 1339,74 & 1891,51 & 1624,43 & 175,34 & 16,07 \\
\hline & PCFV & 18 & 179,82 & 318,82 & 260,99 & 33,63 & \\
\hline \multirow[t]{2}{*}{6} & ICV & 16 & 1392,55 & 1895,40 & 1612,96 & 149,52 & 16,03 \\
\hline & PCFV & 16 & 206,39 & 328,86 & 258,61 & 29,45 & \\
\hline \multirow[t]{2}{*}{7} & ICV & 21 & 1251,94 & 1995,84 & 1642,29 & 203,33 & 17,04 \\
\hline & PCFV & 21 & 241,38 & 367,42 & 279,80 & 33.56 & \\
\hline \multirow[t]{2}{*}{8} & ICV & 18 & 1184.88 & 1761.42 & 1431.63 & 172.81 & 12.78 \\
\hline & PCFV & 18 & 138.07 & 240.15 & 182.93 & 32.08 & \\
\hline \multirow[t]{2}{*}{9} & ICV & 20 & 835.63 & 2122.22 & 1403.61 & 284.41 & 14.89 \\
\hline & PCFV & 20 & 122.50 & 312.50 & 209.04 & 48.11 & \\
\hline \multirow[t]{2}{*}{10} & ICV & 18 & 1059.56 & 1929.78 & 1561.41 & 253.63 & 15.14 \\
\hline & PCFV & 18 & 184.53 & 320.00 & 236.35 & 41.43 & \\
\hline \multirow[t]{2}{*}{11} & ICV & 20 & 1296.71 & 1891.56 & 1572.20 & 168.28 & 15.06 \\
\hline & PCFV & 20 & 181.33 & 327.11 & 236.77 & 38.86 & \\
\hline \multirow[t]{2}{*}{12} & ICV & 19 & 1417.60 & 1830.40 & 1621,96 & 118,74 & 15,06 \\
\hline & PCFV & 19 & 165,33 & 328,53 & 244,28 & 43,27 & \\
\hline \multirow[t]{2}{*}{13} & ICV & 17 & 1310,40 & 1848,89 & 1620,99 & 166,35 & 15,88 \\
\hline & PCFV & 17 & 203,38 & 323,56 & 257,36 & 39,84 & \\
\hline \multirow[t]{2}{*}{14} & ICV & 20 & 1306,67 & 1864,18 & 1624,55 & 144,05 & 14.83 \\
\hline & PCFV & 20 & 188,44 & 321,07 & 240,96 & 31,71 & \\
\hline \multirow[t]{2}{*}{15} & ICV & 18 & 1445,33 & 1929,60 & 1633,64 & 132,74 & 15,04 \\
\hline & PCFV & 18 & 196,44 & 354,13 & 245,64 & 41,65 & \\
\hline \multirow[t]{2}{*}{16} & ICV & 20 & 1442,31 & 1943,20 & 1646,35 & 117,15 & 14,84 \\
\hline & PCFV & 20 & 198,22 & 301,20 & 244,38 & 31,22 & \\
\hline \multirow{2}{*}{17} & ICV & 19 & 1333,33 & 1842,64 & 1639,67 & 133,86 & 15,31 \\
\hline & PCFV & 19 & 191,64 & 316,09 & 251,04 & 33,78 & \\
\hline \multirow[t]{2}{*}{18} & ICV & 20 & 1448,27 & 1883,95 & 1692,25 & 139,04 & 14,31 \\
\hline & PCFV & 20 & 194,84 & 307,56 & 242,15 & 34,36 & \\
\hline
\end{tabular}

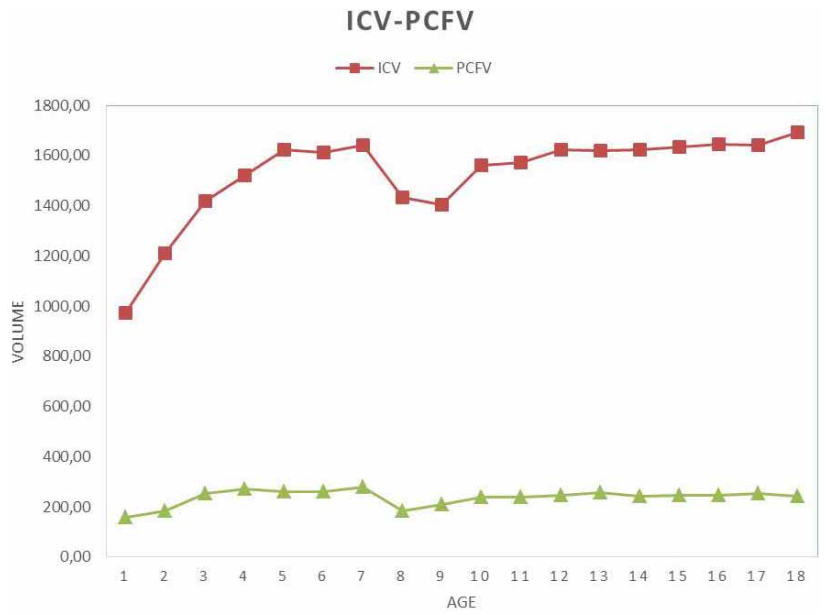

Fig. 2. The volume values of the ICV and PCFV according to age. ICV: Intracranial volume, PCFV: posterior cranial fossa volume.
According to sex the mean ICV and PCFV were $1594.51 \pm 245.57 \mathrm{~cm}^{3}$ and $244.89 \pm 53.86 \mathrm{~cm}^{3}$ in males, $1456.34 \pm 241.85$ $\mathrm{cm}^{3}$ and $228.24 \pm 41.38 \mathrm{~cm}^{3}$ in females, respectively. In addition, there were significant differences in the ICV according to sex in 8 age groups $(4,5,11,14,15,16,17$ and 18 years of age), for PCFV in 7 age groups $(2,8,14,15$, 16,17 and 18 years of age), (Table II). The mean of CEs for the estimation of ICV and PCFV were $2,2.5 \%$, respectively.

When the correlations between the ICV and PCFV measurements statistically analyzed, a positive correlation was determined between the results. Correlation values (r) for ICV and PCFV were determined as 0.604 for females, 0.679 for males respectively $(\mathrm{p}<0.001)$. By the Cavalieri principle (point-counting) using sagittal CT images, the volume ratios of PCF to IC was given (Fig. 3), (Tables I and II). According to age the volume ratios of PCF to IC was ranged from 13.03 to 17.48 in males and 12.06 to 18.54 in females.

\section{DISCUSSION}

ICV is a morphometric measurement of interest in brain disorders and cognitive aging and is used as a proxy for head size. The ICV is directly related to brain growth and is considered to remain relatively stable after brain development ceases in youth (Courchesne et al., 2000; Royle et al., 2013).

\section{VOLUME FRACTION}

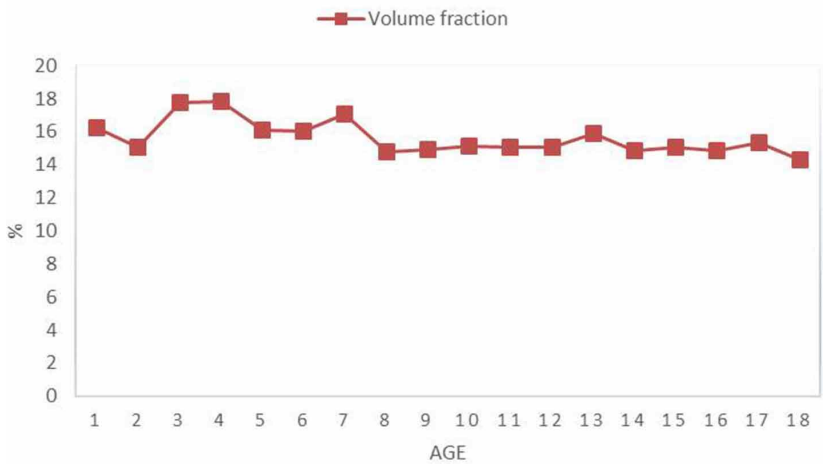

Fig. 3. The volume fraction of the PCFV within the intracranial cavity according to age. 
Table II. The mean volumes of posterior cranial fossa and intracranial cavity calculated by using stereological method in both sexes. The comparison of male-female volume results ( $\mathrm{p}$ values) for each group. ICV: Intracranial volume, PCFV: Posterior cranial fossa volume, ${ }^{*} \mathrm{p}<0.05$.

\begin{tabular}{|c|c|c|c|c|c|c|c|c|c|}
\hline \multirow{2}{*}{$\frac{\text { Age }}{1}$} & \multirow{2}{*}{$\begin{array}{l}\text { Sex } \\
\text { Male }\end{array}$} & \multirow{2}{*}{$\begin{array}{l}\mathrm{N} \\
10\end{array}$} & \multicolumn{2}{|c|}{$\begin{array}{c}\text { ICV } \\
\text { Mean } \pm \text { SD }\end{array}$} & \multirow{2}{*}{$\frac{\mathrm{p}}{0.331}$} & \multicolumn{2}{|c|}{$\begin{array}{c}\text { PCFV } \\
\text { Mean } \pm \text { SD }\end{array}$} & \multirow{2}{*}{$\frac{\mathrm{p}}{0.312}$} & \multirow{2}{*}{$\begin{array}{c}\begin{array}{c}\text { Volume } \\
\text { fraction }\end{array} \\
14.51\end{array}$} \\
\hline & & & 1031.78 & 228.42 & & 149.68 & 31.37 & & \\
\hline & Female & 10 & 913.76 & 295.18 & & 166.02 & 38.45 & & 18.17 \\
\hline \multirow[t]{2}{*}{2} & Male & 8 & 1248.36 & 149.48 & 0.329 & 162.69 & 33.08 & $0.022 *$ & 13.03 \\
\hline & Female & 8 & 1172.15 & 151.72 & & 201.25 & 26.73 & & 17.17 \\
\hline \multirow[t]{2}{*}{3} & Male & 9 & 1500.87 & 155.34 & 0.083 & 255.42 & 43.71 & 0.773 & 17.02 \\
\hline & Female & 10 & 1344.59 & 207.66 & & 249.34 & 46.21 & & 18.54 \\
\hline \multirow[t]{2}{*}{4} & Male & 10 & 1607.42 & 163.00 & $0.045^{*}$ & 278.54 & 47.11 & 0.512 & 17.33 \\
\hline & Female & 10 & 1435.81 & 191.49 & & 264.42 & 47.43 & & 18.42 \\
\hline \multirow[t]{2}{*}{5} & Male & 9 & 1715.11 & 115.20 & $0.023 *$ & 272.21 & 31.47 & 0.163 & 15.87 \\
\hline & Female & 9 & 1533.76 & 183.20 & & 249.77 & 33.62 & & 16.28 \\
\hline \multirow[t]{2}{*}{6} & Male & 8 & 1665.73 & 130.32 & 0.165 & 262.76 & 33.05 & 0.591 & 15.77 \\
\hline & Female & 8 & 1560.18 & 156.72 & & 254.46 & 26.99 & & 16.31 \\
\hline \multirow[t]{2}{*}{7} & Male & 11 & 1673.11 & 198.18 & 0.481 & 292.54 & 40.72 & 0.066 & 17.48 \\
\hline & Female & 10 & 1608.40 & 214.01 & & 265.78 & 15.62 & & 16.52 \\
\hline \multirow[t]{2}{*}{8} & Male & 10 & 1484.40 & 157.43 & 0.153 & 197.48 & 30.11 & $0.026^{*}$ & 13.30 \\
\hline & Female & 8 & 1365.67 & 178.09 & & 164.74 & 25.55 & & 12.06 \\
\hline \multirow[t]{2}{*}{9} & Male & 10 & 1418.25 & 302.71 & 0.825 & 203.25 & 51.72 & 0.604 & 14.33 \\
\hline & Female & 10 & 1388.97 & 280.47 & & 214.84 & 46.23 & & 15.47 \\
\hline \multirow[t]{2}{*}{10} & Male & 9 & 1622.32 & 251.16 & 0.323 & 242.60 & 43.99 & 0.538 & 14.95 \\
\hline & Female & 9 & 1500.50 & 255.48 & & 230.09 & 40.29 & & 15.33 \\
\hline \multirow[t]{2}{*}{11} & Male & 10 & 1660.21 & 147.93 & $0.015^{*}$ & 243.93 & 43.70 & 0.425 & 14.69 \\
\hline & Female & 10 & 1484.18 & 143.81 & & 229.61 & 34.13 & & 15.47 \\
\hline \multirow[t]{2}{*}{12} & Male & 10 & 1664.42 & 93.53 & 0.101 & 231.41 & 50.95 & 0.179 & 13.90 \\
\hline & Female & 9 & 1574.77 & 130.86 & & 258.59 & 29.26 & & 16.42 \\
\hline \multirow[t]{2}{*}{13} & Male & 9 & 1692.89 & 136.00 & 0.055 & 271.71 & 33.92 & 0.118 & 16.05 \\
\hline & Female & 8 & 1540.10 & 167.30 & & 241.22 & 41.84 & & 15.66 \\
\hline \multirow[t]{2}{*}{14} & Male & 10 & 1720.39 & 118.68 & $0.001 *$ & 258.70 & 38.04 & $0.008^{*}$ & 15.04 \\
\hline & Female & 10 & 1528.71 & 154.58 & & 223.22 & 30.22 & & 14.60 \\
\hline \multirow[t]{2}{*}{15} & Male & 8 & 1731.46 & 131.21 & $0.002 *$ & 274.68 & 49.46 & $0.004 *$ & 15.86 \\
\hline & Female & 10 & 1555.38 & 67.69 & & 222.42 & 16.79 & & 14.30 \\
\hline \multirow[t]{2}{*}{16} & Male & 10 & 1728.53 & 89.65 & $0.000 *$ & 268.52 & 24.87 & $0.000 *$ & 15.53 \\
\hline & Female & 10 & 1564.17 & 77.01 & & 220.24 & 22.97 & & 14.08 \\
\hline \multirow[t]{2}{*}{17} & Male & 10 & 1723.93 & 83.22 & $0.001 *$ & 273.00 & 45.08 & $0.001 *$ & 15.84 \\
\hline & Female & 9 & 1546.06 & 117.44 & & 227.00 & 32.06 & & 14.66 \\
\hline \multirow[t]{2}{*}{18} & Male & 10 & 1791.91 & 110.60 & $0.000 *$ & 263.53 & 34.41 & $0.002 *$ & 14.71 \\
\hline & Female & 10 & 1592.59 & 80.67 & & 220.76 & 27.71 & & 13.86 \\
\hline
\end{tabular}

Traditionally, CT scans have been extensively used in craniofacial surgery to confirm the clinical diagnosis of a craniosynostosis, to obtain preoperative information about the underlying brain and to objectively evaluate the surgical results (Posnick et al., 1995). Determination of ICV has been performed for the purpose of surgical planning. The ICV is a good parameter to determine for evaluation of the surgical results, since the operation is a complexre-shaping of the form of the cranium. There is still a controversial discussion concerning the ICV of patients with isolated sagittal synostosis and scaphocephaly as it has been reported by different authors to be greater, less, or equal to the general population (Heller et al., 2008; Fischer et al., 2015). A further problem with ICV measurements has been the absence of adequate reference material and normative aged and sexmatched control groups, based on the same examination skills (Fischer et al.). This raises the question of the validity in regard to the reference group and/or the comparability of the measurement techniques used. Many studies investigated the ICV in healthy and in patients' groups by using automatic, semiautomatic or manual methods (Dale et al., 1999; Jenkinson et al., 2012; Rijken et al., 2015). Although automated methods to stand out in terms of preventing the loss of time, the choice of the software should take into consideration whether the population under study is pediatric or adult. In one study; researchers used four groups including adult controls (AC), adults with Alzheimer's disease (AD), pediatric controls (PC) and group of pediatric epilepsy 
subjects (PE). Three wellknown software packages (FreeSurfer Ver. 5.3.0, FSL Ver. 5.0, SPM8 and SPM12) were examined in their ability to automatically estimate ICV across the groups. SPM12 with the use of pediatric template is found to be a more suitable candidate for PE group. SPM12 and FSL subjected to tuning are the more appropriate tools for the PC group (Sargolzaei et al., 2015). Although there are many studies to prove the accuracy of the automated methods, manual methods are still preferred (Pengas et al., 2009; Nordenskjöld et al., 2013). Many study demostrated that a stereologic technique (point counting) on CT scans may provide unbiased organ volume estimations and their results were similar to gold standard studies (Sahin et al.; Nisari et al.)

One clinical study investigated ICV control (aged 172 \pm 8 days and $10-486$ days.) and sagittal synostosis patients. The ICV was measured in a semi-automatic MATLAB program with functions such as region growing, watershed, and thresholding in axial CT slices. Total mean ICV was calculated $870 \pm 15 \mathrm{ml}$ for the controls. For male and female controls the mean ICV was $883 \pm 18 \mathrm{ml}$ and $834 \pm 28 \mathrm{ml}$, respectively (Fischer et al.). Kamdar et al. (2009) assayed ICV of 123 children (ages at presentation ranged from 8 days to 6 years. At presentation, mean age was 24 months). Intracranial volumes were obtained using a semiautomated image segmentation technique. They determined that ICV was between $200-400 \mathrm{~cm}^{3}$ at newborn, $1200-1400 \mathrm{~cm}^{3}$ at 72 months age. In this study of healthy children, growth is most rapid from birth to 12 months of age, with continued but slower growth during the first 6 years of age, ICV doubled by 9 months of age and tripled by 6 years of age. Sgouros $e t$ al. published a series of intracranial volumes obtained from magnetic resonance imaging data and showed ICV in the first few months of life is on average $900 \mathrm{~cm}^{3}$ in boys and $600 \mathrm{~cm}^{3}$ in girls, increasing to 1300 to $1500 \mathrm{~cm}^{3}$ by 15 years. In the first 2 years, 77 percent of growth was achieved. Freudlsperger et al. (2015) investigated the ICV in 634 healthy boys between the ages of 3 and 13 months by using three dimensional (3D) photogrammetry. The mean total ICV plotted against the age in months increased from $1173.3 \mathrm{~cm}^{3}$ to $1593.6 \mathrm{~cm}^{3}$. Our series of 339 individuals provides the largest series of cranial volume data in children using a proven, accurate technique that we have found in the literature to date, and can provide useful reference in the investigation of any condition influencing cranial vault growth. We determined that at 1 year of age; the mean ICV was $972.77 \pm 263.91 \mathrm{~cm}^{3}$, according to sex mean ICV values were $1031.78 \pm 228.42$ and $913.76 \pm 295.18$ for males and females respectively. Similiar to literature ICV showed that positive correlation to age and growth, is most rapid from birth to the first 5 years of age. Total mean ICV was calculated $1031.78 \pm 228.42 \mathrm{~cm}^{3}$ and male values were greater than female and these differences were statistically significant in some age groups. We thought that numerical differences between present study and literature are possibly due to patients series (age and race) and used methods (radiologic and volume estimation technique).

PCF. The growth of the PCF reflects the way the cerebellum, vermis, brain stem and fourth ventricle develop as a whole. Abnormal changes in the size of the PCF or its contents associated with malformations or functional defects are usually assessed qualitatively. Normative data for the PCFV could be of value in the study of diseases that cause alterations in the size of the PCF (Prassopoulos et al., 1995). A fundamental knowledge of normal anatomy of this region is important to the clinician for diagnosis and treatment (Jha et al., 2008). The differences between the radiographic and the anatomic values and even among the radiographic values are possibly due to the radiologic and other techniques used by the different authors (Prassopoulos et al.). Morphometric analysis of the PCF is required to distinguish clinical cases occurring with a pathologically small PCF from those in which the size and volume of the PCF are normal. When correlated with clinical findings, morphometric assessments of the PCF provide useful clues about the following mechanisms of cerebellar tonsil herniation (CTH): 1- cranial constriction; 2- spinal cord tethering; 3- cranial setting; 4intracranial hypertension and 5-intraspinal hypotension. The differentialdiagnosis of CTH is likely to inform management strategies (Milhorat et al., 2010).

Prassopoulos et al. investigated 181 brain CT examinations, to determine normative data for the PCF in children. The PCFV was calculated by summing consecutive $\mathrm{CT}$ cross-sectional areas. PCFV increased rapidly during the first 3 years of life and thereafter the rate of growth decreased. The PCFV at the age of 3 was $165 \mathrm{~cm}^{3}$ in boys and $155 \mathrm{~cm}^{3}$ in girls and at 15 years, $220 \mathrm{~cm}^{3}$ and $207 \mathrm{~cm}^{3}$ respectively. Trigylidas et al. estimated the volume differences between Chiari I malformations patients and control groups (61 individuals). Volumetric measurements were calculated manually using the Cavalieri method. They were found as $86.76 \mathrm{~cm}^{3}$ for $0-9$ years $(\mathrm{n}=13)$ and $145.14 \mathrm{~cm}^{3}$ for $10-18$ years $(\mathrm{n}=7)$ in control groups. Milhorat et al. calculated PCFV in patients with Chiari malformation and control subjects $(31.7 \pm 11.8$ age) with using radiographic analysis software (ImageJ) and the Cavalieri method on 2D-CT images and PCFV was calculated as $190.1 \pm 7.84 \mathrm{~cm}^{3}$ in control subjects. Similarly, we used individuals between $0-18$ years, in our study, PCFV rised rapidly up to 5 years and positive correlation was found between age and PCVF. We thought that numerical differences among our study and the others may be derived from the subject's race, sex, age, the number differences of the samples and methods that were used in researches. 
Kanodia et al. (2012) investigated 100 consecutive normal computerized tomography (CT) scans of posterior fossa (age ranged from 16 to 89 years with a mean of 51.3 years) and 100 dry adult skulls without any bony abnormality. The PCFV was calculated by two methods. In the first method, volume was calculated by $a b c / 2$, where $a$ is the height, $b$ is AP diameter, and $\mathrm{c}$ is transverse diameter of the PF. In second method, PCFV was calculated by an advanced work station of 16-row bright speed CT scan. The mean value of PCFV where $157.88( \pm 27.94) \mathrm{cm}^{3}$ (range $\left.98.75-216.88 \mathrm{~cm}^{3}\right)$ and $159.58( \pm 25.73) \mathrm{cm} 3$ (range $116.03-252.99 \mathrm{~cm}^{3}$ ) measured by method 1 and method 2, respectively. However, the difference was not statistically significant $(\mathrm{P}>0.05)$. The mean PCFV was $122.49 \mathrm{~cm}^{3}( \pm 14.66)$, respectively, in dry skull. They determined that all the dimensions of PCF were larger in male as compared to female. The volume values calculated with both methods was similar to our results. In our study according to sex; the mean PCFV was determined as $244.89 \pm 53.86 \mathrm{~cm}^{3}$ and $228.24 \pm 41.38 \mathrm{~cm}^{3}$ in males and females respectively. In addition, there was a significant difference in the PCVF according to sex in 7 age groups $(2,8,14,15,16,17$ and 18 years of age) (Table II).

Furtado et al. investigated PCFV in 21 CMI patients, matched with an equal number of pediatric controls by using MR images. They evaluated PCFV to ICV ratio in pediatric CMI patients, adult CMI group and in the pediatric control group. The volume results were obtained by using simple mathematical spheroidal volume formulas. The mean PCFV was $204.1 \mathrm{~cm}^{3}$ in patients with CMI, and $252.8 \mathrm{~cm}^{3}$ in the age and sex matched control group. The number, age and sex distribution of both groups were well matched. There was no statistical difference between ICV in the study and control groups $\left(944.7 \mathrm{~cm}^{3}\right.$ vs. $\left.941.1 \mathrm{~cm}^{3}, \mathrm{p}=0.951\right)$, validating the use of the PFV to ICV ratio to compare the pediatric groups. The PCFV to ICV ratio was significantly lower in patients with CMI than in the control population ( 0.216 vs. $0.268, p=0.001$. There was no significant difference between the PCFV to ICV ratios obtained in the pediatric and adult CMI group (0.216 vs. $0.236, \mathrm{p}=0.1754)$. Similiarly Ventureyra et al. $(2003)$ recorded a statistically smaller PCFV and PCFV to ICV ratio in his series of 61 patients with pediatric CMI.

Researchers demostrated that lower PCFV to ICV ratio which pointing to an overcrowded posterior fossa was important and necessary criterion for the diagnosis and treatment of the disease related to PCF. However, in the analysis of the volume ratio in patients they suggested that a larger study group would have been helpful (Ventureyra et al.; Furtado et al.).

To the best of our knowledge, there was no study in the literature that investigated the development of ICV, PCFV and volume ratios of PCF to IC in children by the stereological technique. In conclusion, we demonstrated increasing ICV and PCFV's in children related to age. In this study, growth is most rapid from from birth to first 5 years of age, ICV and PCFV nearly doubled by 5 years of age. The volume ratios of ICV to PCFV ranged from $13 \%$ to $18 \%$ according to age. We thought that these volume ratios could help the physician for both patient selections for surgery, and for the assessment of any surgical technique used to treatment of PCF malformations. However current study revealed that point counting method can produce accurate volume estimations and is effective in determining volume estimation of intracranial and posterior cranial fossa. The point-counting method is a reliable, simple, inexpensive, and efficient method for estimating volumes in CT images.

ERTEKIN， T.; DEGERMENCI， M.; UCAR， I.; SAGIROGLU, A.; ATAY, E. \& SUSAR, H. Los volúmenes de la fosa craneal intracraneal y posterior y las fracciones de volumen en los niños: un estudio estereológico. Int. J. Morphol., 35(4):1465-1472, 2017.

RESUMEN: El tamaño de la cavidad intracraneal (CI) y la fosa craneal posterior (FCP) desempeñan un papel importante en la fisiopatología de diversos trastornos. En este estudio, se pretende establecer los datos de volumen normal de la CI y FCP en la población turca, de acuerdo a la edad y el sexo, mediante el uso de métodos estereológicos. Este estudio se realizó retrospectivamente en 339 individuos (168 mujeres y 171 hombres) entre 0 y 18 años sin trastornos médicos o neurológicos que afectaron la morfología esquelética de la cavidad craneal. Las estimaciones volumétricas se determinaron en imágenes de tomografía computarizada (TC) utilizando el conteo de puntos de los métodos estereológicos. El volumen intracraneal (VIC) y el volumen posterior de la fosa craneal (VFCP) aumentaron con la edad en ambos sexos. Alcanzaron dimensiones adultas a los 5 años de edad durante la adolescencia. Según el sexo, el promedio de VIC y VFCP fue de $1594,51 \pm 245,57 \mathrm{~cm}^{3}$ y de $244,89 \pm 53,86 \mathrm{~cm}^{3}$ en los hombres, $1456,34 \pm 241,85 \mathrm{~cm}^{3}$ y $228,24 \pm 41,38 \mathrm{~cm}^{3}$ en las mujeres, respectivamente. En general, se determinaron diferencias significativas en VIC y VFCP de acuerdo con el sexo después de alcanzar el período de crecimiento máximo. Según la edad, las proporciones de volumen de FCP a CI oscilaban entre 13,03 a 17,48 en los hombres y 12,06 a 18,54 en las mujeres. Este estudio demostró que estas proporciones de volumen podrían ayudar al médico tanto en la selección de pacientes para la cirugía, como para la evaluación de cualquier técnica quirúrgica utilizada en el tratamiento de malformaciones de FCP. Además, el estudio actual reveló que el método de conteo de puntos puede producir estimaciones precisas de volumen siendo eficaz para determinar la estimación de volumen de IC y FCP.

PALABRAS CLAVE: Tomografía computarizada; Cavidad intracraneal; Fossa craneal posterior; Estereología; Volumen. 


\section{REFERENCES}

Bagley, A. M.; Molitor, F.; Wagner, L. V.; Tomhave, W. \& James, M. A. The Unilateral Below Elbow Test: a function test for children with unilateral congenital below elbow deficiency. Dev. Med. Child Neurol., 48(7):569$75,2006$.

Bambha, J. K. Longitudinal cephalometric roentgenographic study of face and cranium in relation to body height. J. Am. Dent. Assoc., 63:776-99, 1961

Chadha, A. S.; Madhugiri, V. S.; Tejus, M. N. \& Kumar, V. R. The posterior cranial fossa: a comparative MRI-based anatomic study of linear dimensions and volumetry in a homogeneous South Indian population. Surg. Radiol. Anat., 37(8):901-12, 2015.

Courchesne, E.; Chisum, H. J.; Townsend, J.; Cowles, A.; Covington, J.; Egaas, B.; Harwood, M.; Hinds, S. \& Press, G. A. Normal brain development and aging: quantitative analysis at in vivo MR imaging in healthy volunteers. Radiology, 216(3):672-82, 2000

Cruz-Orive, L. M. Stereology of single objects. J. Microsc., 186(2):93-107, 1997.

Dale, A. M.; Fischl, B. \& Sereno, M. I. Cortical surface-based analysis. I. Segmentation and surface reconstruction. Neuroimage, 9(2):179-94, 1999.

Dukart, J.; Mueller, K.; Villringer, A.; Kherif, F.; Draganski, B.; Frackowiak, R.; Schroeter, M. L. \& Alzheimer's Disease Neuroimaging Initiative. Relationship between imaging biomarkers, age, progression and symptom severity in Alzheimer's disease. Neuroimage Clin., 3:84-94, 2013.

Eritaia, J.; Wood, S. J.; Stuart, G. W.; Bridle, N.; Dudgeon, P.; Maruff, P.; Velakoulis, D. \& Pantelis, C. An optimized method for estimating intracranial volume from magnetic resonance images. Magn. Reson. Med., 44(6):973-7, 2000.

Fischer, S.; Maltese, G.; Tarnow, P.; Wikberg, E.; Bernhardt, P.; Tovetjärn, R. \& Kölby, L. Intracranial volume is normal in infants with sagittal synostosis. $J$. Plast. Surg. Hand Surg., 49(1):62-4, 2015.

Freudlsperger, C.; Steinmacher, S.; Bächli, H.; Somlo, E.; Hoffmann, J. \& Engel, M. Metopic synostosis: Measuring intracranial volume change following fronto-orbital advancement using three-dimensional photogrammetry. $J$. Craniomaxillofac. Surg., 43(5):593-8, 2015.

Furtado, S. V.; Reddy, K. \& Hegde, A. S. Posterior fossa morphometry in symptomatic pediatric and adult Chiari I malformation. J. Clin. Neurosci., 16(11):1449-54, 2009.

Gundersen, H. J.; Jensen, E. B.; Kiêu, K. \& Nielsen, J. The efficiency of systematic sampling in stereology--reconsidered. J. Microsc., 193(Pt. 3):199-211, 1999.

Habibi, Z.; Meybodi, A. T.; Maleki, F. \& Tabatabai, S. Superior and anterior inferior cerebellar arteries and their relationship with cerebello-pontine angle cranial nerves revisited in the light of cranial cephalometric indexes: a cadaveric study. Turk. Neurosurg., 21(4):504-15, 2011.

Heller, J. B.; Heller, M. M.; Knoll, B.; Gabbay, J. S.; Duncan, C. \& Persing, J. A. Intracranial volume and cephalic index outcomes for total calvarial reconstruction among nonsyndromic sagittal synostosis patients. Plast. Reconstr. Surg., 121(1):187-95, 2008.

Howard, C. V. \& Reed, M. G. Unbiased Stereology: Three Dimensional Measurement in Microscopy. $2^{\text {nd }}$ ed. Oxford, Liverpool Bios, 2005. pp.55-68.

Ikram, M. A. \& DeCarli, C. Next frontiers in the genetic epidemiology of Alzheimer's disease. Eur. J. Epidemiol., 27(11):831-6, 2012.

Jenkinson, M.; Beckmann, C. F.; Behrens, T. E.; Woolrich, M. W. \& Smith, S. M. FSL. Neuroimage, 62(2):782-90, 2012.

Jha, R. M.; Klimo, P. \& Smith, E. R. Foramen magnum stenosis from overgrowth of the opisthion in a child with achondroplasia. J. Neurosurg. Pediatr, 2(2): 136-8, 2008

Kamdar, M. R.; Gomez, R. A. \& Ascherman, J. A. Intracranial volumes in a large series of healthy children. Plast. Reconstr. Surg., 124(6):2072-5, 2009.

Kanodia, G.; Parihar, V.; Yadav, Y. R.; Bhatele, P. R. \& Sharma, D. Morphometric analysis of posterior fossa and foramen magnum. J. Neurosci. Rural Pract., 3(3):261-6, 2012

Kollias, S. S.; Ball, W. S. Jr. \& Prenger, E. C. Cystic malformations of the posterior fossa: differential diagnosis clarified through embryologic analysis. Radiographics, 13(6):1211-31, 1993.

Mattfeldt, T.; Gottfried, H. W.; Wolter, H.; Schmidt, V.; Kestler, H. A. \& Mayer, J. Classification of prostatic carcinoma with artificial neural networks using comparative genomic hybridization and quantitative stereological data. Pathol. Res. Pract., 199(12):773-84, 2003.
Milhorat, T. H.; Nishikawa, M.; Kula, R. W. \& Dlugacz, Y. D. Mechanisms of cerebellar tonsil herniation in patients with Chiari malformations as guide to clinical management. Acta. Neurochir. (Wien), 152(7):1117-27, 2010.

Nisari, M.; Ertekin, T.; Ozçelik, O.; Cınar, S.; Doganay, S. \& Acer, N. Stereological evaluation of the volume and volume fraction of newborns' brain compartment and brain in magnetic resonance images. Surg. Radiol. Anat., 34(9):825-32, 2012.

Nordenskjöld, R.; Malmberg, F.; Larsson, E. M.; Simmons, A.; Brooks, S. J.; Lind, L.; Ahlström, H.; Johansson, L. \& Kullberg, J. Intracranial volume estimated with commonly used methods could introduce bias in studies including brain volume measurements. Neuroimage, 83:355-60, 2013.

Pengas, G.; Pereira, J. M.; Williams, G. B. \& Nestor, P. J. Comparative reliability of total intracranial volume estimation methods and the influence of atrophy in a longitudinal semantic dementia cohort. J. Neuroimaging, 19(1):37-46, 2009.

Posnick, J. C.; Armstrong, D. \& Bite, U. Metopic and sagittal synostosis: intracranial volume measurements prior to and after cranio-orbital reshaping in childhood. Plast. Reconstr. Surg., 96(2):299-309, 1995.

Prassopoulos, P.; Cavouras, D.; Golfinopoulos, S. \& Nezi, M. The size of the intra- and extraventricular cerebrospinal fluid compartments in children with idiopathic benign widening of the frontal subarachnoid space. Neuroradiology, 37(5):418-21, 1995

Rijken, B. F.; Lequin, M. H.; Van Veelen, M. L.; de Rooi, J. \& Mathijssen, I. M. The formation of the foramen magnum and its role in developing ventriculomegaly and Chiari I malformation in children with craniosynostosis syndromes. J. Craniomaxillofac. Surg., 43(7):1042-8, 2015.

Roberts, N.; Puddephat, M. J. \& McNulty, V. The benefit of stereology for quantitative radiology. Br. J. Radiol., 73(871):679-97, 2000.

Royle, N. A.; Booth, T.; Valdés Hernández, M. C.; Penke, L.; Murray, C.; Gow, A. J.; Maniega, S. M.; Starr, J.; Bastin, M. E.; Deary, I. J. \& Wardlaw, J. M. Estimated maximal and current brain volume predict cognitive ability in old age. Neurobiol. Aging, 34(12):2726-33, 2013

Sahin, B. \& Ergur, H. Assessment of the optimum section thickness for the estimation of liver volume using magnetic resonance images: a stereological gold standard study. Eur. J. Radiol., 57(1):96-101, 2006.

Sahin, B.; Acer, N.; Sonmez, O. F.; Emirzeoglu, M.; Basaloglu, H.; Uzun, A. \& Bilgic, S. Comparison of four methods for the estimation of intracranial volume: A gold standard study. Clin. Anat., 20(7):766-73, 2007.

Sargolzaei, S.; Sargolzaei, A.; Cabrerizo, M.; Chen, G.; Goryawala, M.; Noei, S.; Zhou, Q.; Duara, R.; Barker, W. \& Adjouadi, M. A practical guideline for intracranial volume estimation in patients with Alzheimer's disease. B. M. C. Bioinformatics, 16 Suppl. 7:S8, 2015.

Sgouros, S.; Goldin, J. H.; Hockley, A. D.; Wake, M. J. \& Natarajan, K. Intracranial volume change in childhood. J. Neurosurg., 91(4):610-6, 1999.

Szentkuti, A.; Guderian, S.; Schiltz, K.; Kaufmann, J.; Münte, T. F.; Heinze, H. J. \& Düzel, E. Quantitative MR analyses of the hippocampus: unspecific metabolic changes in aging. J. Neurol., 251(11):1345-53, 2004.

Trigylidas, T.; Baronia, B.; Vassilyadi, M. \& Ventureyra, E. C. Posterior fossa dimension and volume estimates in pediatric patients with Chiari I malformations. Child. Nerv. Sys., 24(3):329-36, 2008.

Tubbs, R. S.; Hill, M.; Loukas, M.; Shoja, M. M. \& Oakes, W. J. Volumetric analysis of the posterior cranial fossa in a family with four generations of the Chiari malformation Type I. J. Neurosurg. Pediatr., 1(1):21-4, 2008.

Ventureyra, E. C.; Aziz, H. A. \& Vassilyadi, M. The role of cine flow MRI in children with Chiari I malformation. Childs Nerv. Syst., 19(2):109-13, 2003.

Wang, H.; Rosenbaum, A. E.; Reid, C. S.; Zinreich, S. J. \& Pyeritz, R. E. Pediatric patients with achondroplasia: CT evaluation of the craniocervical junction. Radiology, 164(2):515-9, 1987.

\section{Corresponding author: \\ Tolga Ertekin}

Associated Professor - Department of Anatomy

University of Afyon Kocatepe - School of Medicine

Afyonkarahisar - TURKEY

\section{E-mail: tolga.ertekin@yahoo.com.tr Received: 21-03-2017}

Accepted: 11-08-2017 